\title{
Late Preterm Infant
}

National Cancer Institute

\section{Source}

National Cancer Institute. Late Preterm Infant. NCI Thesaurus. Code C114938.

A newborn infant greater than or equal to 34 weeks, 0 days and less than 37 weeks, 0 days gestational age. 